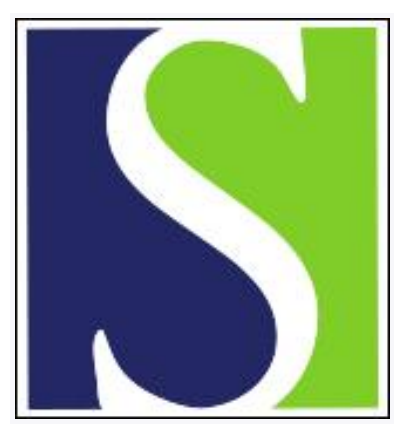

Scand J Work Environ Health 1984;10(6):443-449

https://doi.org/10.5271/sjweh.2314

Issue date: Dec 1984

Tenosynovitis, peritendinitis and the tennis elbow syndrome.

by Viikari-Juntura $\mathrm{E}$

This article in PubMed: www.ncbi.nlm.nih.gov/pubmed/6398912

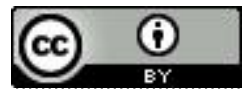




\title{
Tenosynovitis, peritendinitis and the tennis elbow syndrome
}

\author{
by Eira Viikari-Juntura, MD ${ }^{1}$
}

\begin{abstract}
VIIKARI-JUNTURA E. Tenosynovitis, peritendinitis and the tennis elbow syndrome. Scand $J$ Work Environ Health 10 (1984) 443-449. Both tenosynovitis and peritendinitis of the wrist and forearm and the tennis elbow syndrome are common problems among industrial workers. Yet not much is known of the etiology of these diseases and, especially, of the role of mechanical factors in the etiology. The role of different causative factors is usually studied through comparison of the occurrence rates of the disease in differentially exposed working populations. However, not many such epidemiologic studies have been done. That repetitive movements in manual work may cause tenosynovitis or peritendinitis is generally accepted. Efforts to study further movements and the work positions at fault have, however, failed to show any single set of movements or hand positions. It is often postulated that movements such as repetitive dorsiflexions of the wrist and prosupinations of the forearm are causative for the tennis elbow syndrome, but there is no scientific proof for this argumentation. There are also several proposed mechanisms for the pathogenesis of the disease. In the treatment of the acute phase of these diseases in an occupational health setting, rest for the affected limb is essential. Prevention of the diseases and their recurrences probably requires changes in work conditions. Yet, at the moment, there is not much scientific basis for these measures.
\end{abstract}

Key terms: epicondylitis, lateral elbow pain, repetitive work, rheumatic diseases, treatment.

Tenosynovitis and peritendinitis of the wrist and forearm and the tennis elbow syndrome are said to be common problems among industrial workers. Most data concerning these diseases are based on clinical case series or occupational health center records. As persons whose disease is severe or prolonged or whose occupation is strenuous are more easily referred for examination, these data are not representative of the average disease in working populations. In addition such data are biased and cannot be used for studies on the relation between work and these diseases.

\section{Tenosynovitis and peritendinitis}

The terminology used for the disorders of the tendon and its adjacent structures is not well-defined. In a recent review (23) tenosynovitis was used for the inflammation of the tendon sheath, and peritendinitis for the inflammation of the paratenon all the way to the area of the muscle-tendon junction (figure 1). Thus, in the arm, the location of tenosynovitis is in and about the wrist, and the location of peritendinitis is higher up in the forearm. When the movement of a tendon within its sheath is restricted, eg, because of thickening of the tendon or the sheath, stenosing tenosynovitis may result. Stenosing tenosynovitis of the

1 Department of Physiology, Institute of Occupational Health, Helsinki, Finland.

Reprint requests to: Dr E Viikari-Juntura, Institute of Occupational Health, Laajaniityntie 1, SF-01620 Vantaa, Finland. long abductor and short extensor of the thumb at the radial styloid process is called de Quervain's disease. In stenosing tenosynovitis of the flexor tendons of the fingers, a local swelling may develop and cause triggering of the fingers (27).

The tendons most frequently affected have been the long abductor and short extensor of the thumb and the radial extensors of the wrist, lesions of the flexor tendons being far less common $(17,28,29)$. In one case series comprising 544 tenosynovitis and peritendinitis cases in industry (30), the lesion was peritendinitis in 419 and tenosynovitis in 125 cases. In most other studies $(25,29)$ a clear distinction between tenosynovitis and peritendinitis has not been made.

\section{Etiology}

Kurppa et al (23) recently reviewed the etiology of peritendinitis and tenosynovitis. Overexertion was considered the most important etiologic factor, although it was emphasized that scientific proof for this argumentation is lacking. Change of daily routine, such as resumption of new tasks or return from a leave have often triggered the disease (30). Blunt trauma and sprain have fairly often preceded the symptoms, whereas other causes (rheumatic, tuberculotic, luetic, gonorrheal) play a minor role in the etiology (23).

There is only one study on the etiology with a reference group (24). In a cross-sectional examination, Luopajärvi and her co-workers found "muscletendon syndrome" in $85(56 \%)$ of 152 assembly-line 


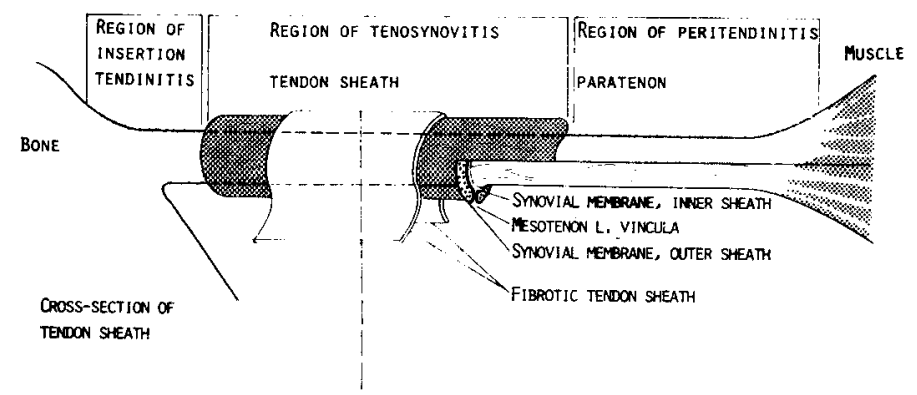

FIBROTIC TENDON SHEATH

SWOVIAL MEMERANE, INWER SHEATH -(f)

SMOVIal memerane, OATER SHEath
Mesotenon L, vincula

Figure 1. Location of tenosynovitis and peritendinitis in the muscle-tendon unit [reprinted from Kurppa et al (23)].

packers and in $18(14 \%)$ of 133 shop assistants. The prevalences, obtained through the use of a clinical examination with given diagnostic criteria, are rather high, and, as stated by the authors, probably are not representative of the actual occurrences of tenosynovitis and peritendinitis. However, the muscle-tendon syndrome was far more common in packers, whose work includes repetitive motions of fingers and hands at high speed, extreme positions of the hands, and static muscle work of the arm and shoulder muscles.

On the other hand, rather different occurrence rates have also been obtained. In a cross-sectional study among a selected group of 113 meatcutters, butchers, and meat by-product workers who worked in a cold environment $\left(10^{\circ} \mathrm{C}\right)$, only four persons with peritendinitis were found (34). The diagnosis was based on a thorough physical examination with strict criteria. This wide range of occurrence rates from different studies suggests that differences between results are probably due to the method used and the interindividual variation between the examiners in performing the physical examination rather than to differences in the occurrences of the disease in various work groups.

The pace and the biomechanics of the tasks in which tenosynovitis and peritendinitis have occurred have not, as yet, received much attention. Kuorinka \& Koskinen (20) clinically examined 93 workers performing manual operations in the scissor-making process and found 17 workers with muscle-tendon syndrome. The work analysis was made according to task characteristics (manipulation/inspection), cycletime (short cycle/long cycle), wrist-joint deviation, and total work load during the investigation year. The presence of muscle-tendon syndrome did not correlate with any of these work determinants. However, of the subjects with muscle-tendon syndrome, those with the greatest total work load had the most objective signs of the disease.

\section{Pathogenesis}

The pathogenesis of tenosynovitis and peritendinitis has been studied by Howard (17), Lipscomb (25), and Rais (28). They agree that there is edema and accumulation of fibrin in the tendon sheath, paratenon, or muscle interstitium. Later, fibroblastic proliferation is noticed. In his experimental studies on rabbits, Rais (28) found different degenerative changes in the muscle to be dependent on the amount of physical exercise. The most pronounced degenerative changes were not encountered in man, as pain probably prevents further exercise. In peritendinitis, the pathological changes were usually in the paratenon and muscle interstitium with no changes in the tendon and tendon sheath.

\section{Treatment}

Most articles concerning the treatment of tenosynovitis and peritendinitis are more descriptions of therapy than critical evaluations of it.

The conventional treatment for tenosynovitis has been immobilization $(8,14,17,30)$, often combined with physical therapy. According to Howard (17), adequate immobilization is important and gives an average disability of $11.6 \mathrm{~d}$. Furthermore heat, massage, and motion are not considered important. Thompson et al (30), as well as some other authors (14), consider rigid splinting worse (recovery period four weeks) than a detachable splinting that permits slight movement in the splint (recovery period $12 \mathrm{~d}$ ). According to Thompson et al cessation of work was neither desirable nor necessary. He considered shortwave therapy valuable. As the tendons of the thumb are often involved, immobilization of the thumb is important $(17,30)$.

Different forms of physical therapy are used widely nowadays. As has already been noted, opinions on their effect differ. Unfortunately, controlled studies are extremely few. Videman and his coworkers (33) compared diadynamic currents, a form of electrotherapy, with placebo, in the treatment of acute tenosynovitis and peritendinitis and found no difference in the recovery period. In fact, there are no properly controlled studies to show any positive effects of physical therapy.

In recent studies, cortisone preparations have been used primarily in the treatment of de Quervain's 
stenosing tendovaginitis and the relatively rare cases of flexor tenosynovitis (13). When small groups of patients with peritendinitis have been treated with cortisone, various results have been obtained (28).

Intravenous heparin in the treatment of crepitating peritendinitis has given the best results. In an extensive controlled study on 223 patients by Rais (28), the recovery period after intravenous heparin treatment was $3.6 \mathrm{~d}$. The reference groups were a small group treated with sodium chloride and a group of patients with peritendinitis treated with conventional methods during the five preceding years at a surgical out-patient department, the recovery periods being 13.5 and $16.3 \mathrm{~d}$, respectively.

Surgical treatment has been used mostly for trigger finger and stenosing tenosynovitis (25).

\section{Tenosynovitis and peritendinitis in an occupational health setting}

In an occupational health setting, tenosynovitis and peritendinitis often present a problem. There are many questions that should be answered before a worker is treated or the disease can be prevented. The following list gives some examples:

Are the mechanical factors of specific tasks at fault?

Are there any means for identifying the persons at risk?

Which is the most effective and suitable form of therapy in an occupational health setting?

How often does the disease recur?

What is the long-term prognosis of the worker with repeatedly occurring tenosynovitis or peritendinitis, if he resumes previous tasks?

It is believed that the speed and mechanical factors of work are decisive for the development of peritendinitis and tenosynovitis. However, in the aforementioned study of Kuorinka \& Koskinen (20) no correlation between these factors and the occurrence of the diseases was found. No other studies on this subject have been made. Thus data are poor with respect to identifying possible deleterious components in specific tasks.

Only some workers in similar manual tasks contract tenosynovitis or peritendinitis. Thus it is possible that individual characteristics (eg, tissue structure, psychomotor skill) participate in the pathogenetic chain of the disease process. These individual predisposing factors should be studied so that susceptible persons can be identified.

A vibration test for screening workers susceptible to tenosynovitis has been introduced by Hettinger $(15,16)$. However Kuorinka and his co-workers (21) later found that the test discriminated very poorly between healthy workers and those that had had tenosynovitis. The intraindividual variation in the test results was even so great that they did not recommend the test for screening purposes. So far, no other means for screening for a predisposition towards tenosynovitis has been presented.

Although, as has already been stated, some modes of treatment (detachable splinting, heparin) have been superior to others, their use in an occupational health setting today needs further consideration. The work movements of many manual tasks are fairly fixed and not possible to perform with a splint in place. Furthermore a change of tasks is not easily realized in many work organizations. In addition, as the work movements of repetitive tasks are probably often at least contributors to, if not causes of, the disease, cessation of work or a change of tasks for some period is often necessary.

As already stated, heparin seems to be the drug of choice for crepitating peritendinitis. There is, however, a rare contraindication of bleeding diatheses. Moreover, although Rais encountered adverse reactions, most of which were mild, in only 5 of 160 treated patients, even anaphylaxis can occur (11). Thus, it can reasonably be questioned whether an intravenous injection of heparin should be widely used in an occupational health setting.

Clinical experience suggests that tenosynovitis and peritendinitis recur in a considerable number of cases, either in the same or another location. In Thompson's 419 cases of peritendinitis of the forearm (30), there were 93 recurrences shortly after the treatment was terminated, and 20 recurrences months or years later. Some workers change their work because of recurrences. Yet no appropriate data on these phenomena are available from any type of industry.

\section{Tennis elbow syndrome}

The terms tennis elbow syndrome, lateral epicondylitis, and lateral elbow pain are used for a painful condition at or about the lateral epicondyle of the humerus. The clinical picture is often fairly uniform, although the pathomechanism by which the symptoms are produced may vary.

\section{Etiology}

Exertion of the finger and wrist extensors and trauma to the epicondyle are commonly presented as etiologic factors for the tennis elbow syndrome (22). Goldie (12) analyzed 113 patients who were operated on because of lateral epicondylitis. Repeated dorsiflexions of the hand or alternating pronations and supinations were considered etiologic factors in 83 cases, trauma was involved in 29 cases, and in 1 case the etiology was unknown. Thirty-three patients reported that the symptoms had arisen within two to three weeks after they changed work, and 50 patients 
Table 1. Occurrence rates of lateral epicondylitis in different studies.

\begin{tabular}{|c|c|c|c|c|}
\hline & \multicolumn{4}{|c|}{ Study group } \\
\hline & $\begin{array}{l}\text { Normal } \\
\text { population a } \\
(\mathrm{N}=15268) \\
\end{array}$ & $\begin{array}{l}\text { Assembly-line } \\
\text { packers b } \\
(N=152)\end{array}$ & $\begin{array}{l}\text { Shop } \\
\text { assistants b } \\
(N=133)\end{array}$ & $\begin{array}{l}\text { Slaughterhouse } \\
\text { workers } \\
(N=133)\end{array}$ \\
\hline Gender & $\begin{array}{l}\text { Males and females, } \\
\text { exact proportions } \\
\text { not available }\end{array}$ & Females & Females & $\begin{array}{l}82 \text { males } \\
31 \text { females }\end{array}$ \\
\hline Age (years) & Range $31-74$ & Mean 39 (SD 9) & Mean 39 (SD 11) & Mean 32 (SD 9) \\
\hline Study design & $\begin{array}{l}\text { Cross-sectional, } \\
\text { follow-up } 8-27 \\
\text { months }\end{array}$ & Cross-sectional & Cross-sectional & Cross-sectional \\
\hline Occurrence & $\begin{array}{l}\text { Prevalence } 1-3 \% \\
\text { (females aged } \\
42-46 \text { years, } 10 \% \text { ), } \\
\text { annual incidence } \\
\leq 1 \%\end{array}$ & Prevalence $3 \%$ & Prevalence $2 \%$ & Prevalence $0 \%$ \\
\hline
\end{tabular}

a From Allander (1, 2).

b From Luopajärvi et al (24).

c From Viikari-Juntura (34).

were doing work that they were used to at the time of occurrence.

Analyses of clinical case series have led to assumptions that the tennis elbow syndrome is caused by different repetitive manual tasks. Yet the role of work in its etiology has been studied very little with the use of a properly controlled methodology.

In their cross-sectional study, Luopajärvi and her co-workers (24) found 4 workers with lateral epicondylitis among 152 assembly-line packers and 3 shop assistants with the same syndrome out of a total of 133 (table 1). In a cross-sectional study of 113 slaughterhouse workers (34) no cases of epicondylitis were found (table 1). On the other hand Allander (2) found the considerable prevalence of $1-3 \%$ for lateral epicondylitis even in a normal population between the ages of 31 and 74 years (table 1). A surprisingly high prevalence of $10 \%$ was reported for women aged $42-46$ years. These prevalences are, however, high when compared with the given annual incidences of $1 \%$ and less. The duration of lateral epicondylitis is usually reported to be from some weeks to some months, but the occurrence rates of Allander's study are suggestive of a more chronic condition. Occupations were not reported in this study.

The results from the cross-sectional studies mentioned do not offer many conclusions. They show, however, that the prevalences of epicondylitis are not necessarily the highest in populations doing repetitive and strenuous manual tasks. No follow-up studies of working populations have been made.

\section{Pathogenesis}

There are various concepts of the pathogenesis of the tennis elbow syndrome. On the basis of clinical findings and results of treatment of 20 patients, Cyriax (6) came to the conclusion that a typical tennis elbow is caused primarily by a tear between the tendinous origin of the extensor carpi radialis brevis and the periosteum of the lateral epicondyle. This theory has been supported by Coonrad \& Hooper (5), who found macroscopic tears of the common extensor or flexor tendon in 28 and scar tissue replacement in 9 of the 39 patients that they had operated on. However, surgeons have often failed to find these tears $(9$, $10)$.

Goldie (12) suggested that there is a subtendinous space distal to the epicondyle and beneath the aponeurosis. In his patients with lateral epicondylitis this space was filled with granulomatous tissue, which was believed to be the primary pathological change in the disease. The findings of Goldie have not been confirmed by later studies $(5,10)$.

Synovitis of the radiohumeral joint (9) and degeneration of the orbicular ligament around the head of the radius (4) have often been proposed to be the primary pathological changes.

Neuritis of the articular branches of the radial nerve was suggested by Kaplan (18) as a pathomechanism of the tennis elbow syndrome. Posterior interosseus nerve entrapment, ie, the entrapment of the deep branch of the radial nerve, which is also called Frohse's syndrome, should be considered a separate disease, although the clinical picture may resemble that of lateral epicondylitis. Werner (32) estimated that nerve entrapment could be diagnosed in approximately $5 \%$ of patients with lateral elbow pain.

Since the mean age of workers with lateral epicondylitis is, in most case series, over 40 years, one would be inclined to think that degeneration has a role in the pathophysiology of the disease. Degeneration in the common extensor origin and adjacent structures between the ages 20 and 50 years was not, however, demonstrable by Goldie (12). That there was a decreasing incidence and prevalence of epicondylitis with age in Allander's population study (2) suggests that degeneration is not important in the pathogenesis of the disease either. On the other hand diminished exertion in advancing age may render the disease symptomless. 
Murray-Leslie \& Wright (26) noticed that, among patients with carpal tunnel syndrome, more cases of lateral epicondylitis occurred than among referents. Furthermore those who had both carpal tunnel syndrome and epicondylitis had the smallest anteroposterior diameter of the cervical spinal canal. There is no clear interpretation for these results, but they suggest that there are individual predisposing factors for these diseases. Yet it is not known whether these relations hold true for working populations.

\section{Treatment}

There is a variety of different types of both conservative and operative treatment for tennis elbow syndrome (9), probably because the pathomechanism of the disease varies and is often not known. Unfortunately, evaluations of different therapies are only rarely based on controlled studies. Only the most popular forms of treatment have been described in the following discussion.

The short-term results of cortisone therapy are often good (13). Day and his co-workers (7) compared the results of injections of methylprednisolone, $1 \%$ xylocaine, and $0.9 \%$ saline in 95 tennis elbow patients. In this study, the initial outcome in the group treated with methylprednisolone was clearly superior to the results of the groups treated with xylocaine and saline, whereas no differences were found between the two latter therapies.

Ultrasound is probably the mode of physical therapy most used in the treatment of tennis elbow $(3,9$, $19,34)$. However, there are no properly controlled studies to show its value. In the before mentioned controlled study (33), diadynamic currents were not superior to a placebo in the treatment of epicondylitis.

A detachable wrist splint that allows free movement for the fingers has been used to treat tennis elbow syndrome. In a case series of 88 workers visiting an occupational health center (19), splint therapy combined with indomethacin was compared to two cortisone preparations. Neither duration of absence from work nor the long-term results after one year differed between these three groups of workers. Athletes use a tennis elbow brace, which is bound firmly around the upper part of the forearm, to diminish stress to the epicondyle during exertion.

Surgical therapy is nowadays used for prolonged cases in which conservative therapy has failed. In the occupational health center material already mentioned (19), 2 of 88 workers with epicondylitis were operated on.

The duration of the tennis elbow syndrome is usually said to be from some weeks to some months. According to Cyriax (6) the tennis elbow syndrome usually clears up in 8 to 12 months without any treatment. However in a prospective study on 60 tennis elbow patients in a rheumatology clinic (3), when symptoms were inquired about after one year, 30 had intermittent discomfort, and 13 severe pain. Thus the tennis elbow syndrome may sometimes be a rather long-lasting condition. Accordingly it would be interesting and important to know whether the therapies used have any effect on the natural course of the disease. Yet this question has not been studied.

\section{Tennis elbow syndrome in an occupational health setting}

Present knowledge on the etiology of the tennis elbow syndrome is limited. Whether a scar in the common extensor tendon, granulomatous tissue in the subtendinous space, or neuritis of the radial nerve is the pathological change occurring in tennis elbow syndrome, one could speculate that overexertion of the wrist and finger extensors could initiate and contribute. However there are no well-based data on risk occupations. Neither have any possible causative movements been properly analyzed. Thus there is not much basis for prevention of the disease. Susceptible individuals cannot be identified either.

The occupation of a worker with tennis elbow should be considered when treatment is chosen. In mild cases of epicondylitis a detachable wrist splint or a tennis elbow brace may alleviate the pain of movement enough to allow the worker to continue work. The wrist splint is better suited for use in physically light tasks, and the tennis elbow brace is appropriate for dynamic forceful movements. The advantage of these mechanical aids is that they have no adverse effects.

Although corticosteroids are considered of value, they were not superior to the combined use of splint and indomethacin in the study of a working population (19). Furthermore, as corticosteroids have known adverse effects, their use in an occupational health setting should be carefully considered in each case.

The tennis elbow syndrome is usually said to be self-limiting. Still clinical experience has shown that there is a small number of persons who have a painful and long-lasting disease which is resistant to all therapy. Somer workers do not return to their previous tasks. In worklife these cases present a problem, as the disease occurs most often at an age when a change in task or occupation is not easily accomplished.

\section{Problems in research}

For reliable data on the relation of work with tenosynovitis, peritendinitis, and the tennis elbow syndrome, controlled studies of the occurrence rates of these diseases should be done for different working populations. Answers to the other questions presented also require studies on workers.

These studies face many methodological problems however. The cases should be identified in a clinical examination, as no other reliable means (laboratory, 
radiological) exist. Estimation of the occurrence of these diseases cannot be based on symptom inquiries, as these diseases account for only a part of wrist and elbow symptoms.

There are also many difficulties involved with a clinical examination for such diseases. First of all, although seemingly consistent and detailed criteria have been suggested for these diseases $(12,31)$, repeating the examination exactly in the way presented may be difficult. Problems arise because neither the questions on symptoms nor the methods for performing single clinical tests (eg, location and force of palpation, positioning of the arm in functional tests) have been standardized. Standardization of the clinical examination is important for the reliability and inner validity of the study.

Moreover, it can be expected that workers with tenosynovitis or epicondylitis symptoms easily change jobs. On the other hand it is possible that susceptible individuals avoid strenuous and repetitive manual tasks. Because of this selection many definite cases of disease may not be found in a working population. Thus most objective signs are marginal, and drawing a line between a negative and positive finding may be difficult.

In addition, when strict criteria for a disease are used, the prevalences of the diseases in working populations may be small (34). Thus large populations may be needed to obtain a sufficient number of cases.

Although many measurement techniques for systematically describing manual work have been developed, the analysis of work methods is difficult and laborious. Work movements are many and complex even in monotonous manual tasks. Therefore much work is needed if one wants to know more of the quantity and quality of the work movements at fault.

\section{References}

1. Allander E. A population survey of rheumatoid arthri tis. Acta Rheumatol Scand (1970): suppl 15, 146 p.

2. Allander E. Prevalence, incidence and remission rates of some common rheumatic diseases or syndromes. Scand J Rheumatol 3 (1974) 145-153.

3. Binder AI, Hazleman BL. Lateral humeral epicondylitis - A study of natural history and the effect of conservative therapy. $\mathrm{Br} \mathrm{J}$ Rheumatol 22 (1983) $73-76$.

4. Bosworth DM. The role of the orbicular ligament in tennis elbow. J Bone Jt Surg 37 A (1955) 527-533.

5. Coonrad RW, Hooper R. Tennis elbow: Its course, natural history, conservative and surgical management. J Bone Jt Surg 55 A (1973) 1177-1182.

6. Cyriax JH. The pathology and treatment of tennis elbow. J Bone Jt Surg 18 (1936) 921-940.

7. Day BH. Corticosteroid injections in the treatment of tennis elbow. Practitioner 220 (1978) 459-462.

8. Ellis M. Tenosynovitis of the wrist. Br Med J 2 (1951) $777-779$.

9. Friedlander HL, Reid RL, Cape RF. Tennis elbow. Clin Orthop 51 (1967) 109-116.

10. Garden RS. Tennis elbow. J Bone Jt Surg 43 B 1 (1961) $100-106$.
11. Gervin AS. Complications of heparin therapy. Surg Gynecol Obstet 140 (1975) 789-796.

12. Goldie I. Epicondylitis lateralis humeri (Epicondylitis or tennis elbow): A pathogenetical study. Acta Chir Scand Suppl 339 (1964) 1-119.

13. Gray RG, Tenenbaum J, Gottlieb NL. Local corticosteroid injection treatment in rheumatic disorders. Semin Arthritis Rheum 10 (1981) 231-254.

14. Griffiths DLL. Tenosynovitis and tendovaginitis. $\mathrm{Br}$ Med J 1 (1952) 645-647.

15. Hettinger $T$. Ein Test zur Erkennung der Disposition zu Sehnenscheidenentzündungen. Int $Z$ angew Physiol einschl Arbeitsphysiol 16 (1957) 472-479.

16. Hettinger T. Eine Modiffikation des Hauttemperaturtestes zur Erkennung der Disposition zu Sehnenscheidenentzündungen. Int $Z$ angew Physiol einschl Arbeitsphysiol 17 (1958) 271-276.

17. Howard NJ. A new concept of tenosynovitis and the pathology of physiologic effort. Am J Surg 42 (1938) $723-730$.

18. Kaplan EB. The etiology and treatment of epicondylitis. Bull Hosp Jt Dis 29 (1968) 77-83.

19. Kivi $\mathbf{P}$. The etiology and conservative treatment of humeral epicondylitis. Scand J Rehabil Med 15 (1982) $37-41$.

20. Kuorinka I, Koskinen P. Occupational rheumatic diseases and upper limb strain in manual jobs in a light mechanical industry. Scand J Work Environ Health 5 (1979): suppl 3, 39-47.

21. Kuorinka I, Videman T, Lepistö M. Reliability of a vibration test in screening for predisposition to tenosynovitis. Eur J Applied Physiol 47 (1981) 365-376.

22. Kurppa K, Waris P, Rokkanen P. Tennis elbow: Lateral elbow pain syndrome. Scand $\mathbf{J}$ Work Environ Health 5 (1979): suppl 3, 15-18.

23. Kurppa K, Waris P, Rokkanen P. Peritendinitis and tenosynovitis: A review. Scand J Work Environ Health 5 (1979): suppl 3, 19-24.

24. Luopajärvi T, Kuorinka I, Virolainen M, Holmberg M. Prevalence of tenosynovitis and other injuries of the upper extremities in repetitive work. Scand $J$ Work Environ Health 5 (1979): suppl 3, 48-55.

25. Lipscomb PR. Chronic nonspecific tenosynovitis and peritendinitis. Surg Clin North Am 24 (1944) 780797.

26. Murray-Leslie CF, Wright V. Carpal tunnel syndrome, humeral epicondylitis, and the cervical spine: A study of clinical and dimensional relations. $\mathrm{Br}$ Med $\mathrm{J} \mathrm{I}$ (1976) 1439-1442.

27. Phalen GS. Stenosing tenosynovitis: Trigger fingers and trigger thumb, de Quervain's disease, acute calcification in wrist and hand. In: Flynn JE, ed. Hand surgery. Williams \& Wilkins Company, Baltimore, MD 1975, pp 338-347.

28. Rais $\mathrm{O}$. Heparin treatment of peritenomyosis (peritendinitis) crepitans acuta. Acta Chir Scand Suppl 268 (1961) $11-42$ \& 77-88.

29. Reed JV, Harcourt AK. Tenosynovitis, an industrial disability. Am J Surg 62 (1943) 392-396.

30. Thompson AR, Plewes LW, Shaw EG. Peritendinitis crepitans and simple tenosynovitis: A clinical study of 544 cases in industry. Br J Ind Med 8 (1951) 150-158.

31. Videman $T$, Waris $P$, Heikkilä $J$, Hämäläinen $O$, Remes L, Luopajärvi T. Diadynaamiset virrat tenosynoviitin, peritendiniitin ja epikondyliitin hoidossa. Suom Lääkäril 1-2 (1982) 28-31.

32. Viikari-Juntura E. Neck and upper limb disorders among slaughterhouse workers: An epidemiologic and clinical study. Scand J Work Environ Health 9 (1983) 283-290.

33. Waris P, Kuorinka I, Kurppa K, Luopajärvi T, Virolainen M, Pesonen K, Nummi J, Kukkonen R. Epidemiologic screening of occupational neck and upper 
limb disorders: Methods and criteria. Scand J Work

Environ Health 5 (1979): suppl 3, 25-38.

34. Werner C-O. Lateral elbow pain and posterior interosseous nerve entrapment. Acta Orthop Scand Suppl
174 (1979) $1-35$.

35. Winterfeld H-J. Möglichkeiten der Gleichschall- und Impuls-Ultraschall-Behandlung bei der Epikondylitis humeroradialis. Z ärztl Fortbild 76 (1982) 594-595. 